\title{
Dense Nanostructured Nickel Produced by SPS from Mechanically Activated Powders: Enhancement of Mechanical Properties
}

\author{
F. Naimi, ${ }^{1}$ L. Minier, ${ }^{1}$ S. Le Gallet, ${ }^{1}$ H. Couque, ${ }^{2}$ and F. Bernard ${ }^{1}$ \\ ${ }^{1}$ ICB UMR 6303 CNRS/Université de Bourgogne, BP 47870, 21078 Dijon Cedex, France \\ ${ }^{2}$ Nexter Munitions, 7 route de Guerry, 18000 Bourges, France \\ Correspondence should be addressed to F. Bernard; fbernard@u-bourgogne.fr
}

Received 25 February 2013; Accepted 16 April 2013

Academic Editor: Faming Zhang

Copyright (c) 2013 F. Naimi et al. This is an open access article distributed under the Creative Commons Attribution License, which permits unrestricted use, distribution, and reproduction in any medium, provided the original work is properly cited.

\begin{abstract}
An investigation was performed to evaluate the potential of the spark plasma sintering process in producing dense nanostructured materials. Microstructured and nanostructured nickel was sintered by SPS starting from nickel powder (APS 3-7 $\mu \mathrm{m}$ ) in the asreceived state and after a mechanical activation using a high-energy ball mill. First, a sintering study to determine SPS processing conditions to reach full densification was carried out with specimens $50 \mathrm{~mm}$ in diameter and $10 \mathrm{~mm}$ in height. In a second step, an experimental investigation was undertaken with dense nickel disks to generate tensile properties. The tensile tests were performed at a strain rate of $10^{-3} \mathrm{~s}^{-1}$ with specimens $16 \mathrm{~mm}$ in gage length and $4 \mathrm{~mm}$ in gage diameter. Tensile ductility in excess of $40 \%$ was reached with the microstructured nickel. For the nanostructured nickel, high yield stresses in excess of $600 \mathrm{MPa}$ were measured with a tensile ductility of $30 \%$. These results were analyzed through densification and microstructure measurements.
\end{abstract}

\section{Introduction}

The term "nanomaterials" is usually used for nanostructured or nanophased materials, in which the dimension of grains is ranged from 1 to 100 nanometers, which have specific characteristics due to the modification of the surface/volume ratio. However, if many examples in the literature can easily illustrate these effects in electronics, magnetic recording, cosmetics, catalysis, etc. [1-7], it is very difficult to access to the evolution of mechanical properties versus the grain size. The relative dearth of experimental data on mechanical properties of nanomaterials has been attributed to the difficulty in preparing significant size dense specimens [8]. Nevertheless, some examples showed clearly that the improvement of mechanical properties of metals and alloys is historically related to a refinement of microstructure. Indeed the decreasing of the grain size increases the yield strength according to the Hall-Petch law [9-11]. The development of substructure limits the dislocation motions via the precipitation-creation of dislocation cells (10-200 nm) - and, consequently, reinforces the compromise between yield stress and ductility [12].
For example, in the case of tungsten alloys prepared by powder metallurgy and thermal transformation, an increasing by two orders of magnitude of strength resistance is observed [13].

Material processing via powders has the potential of controlling the material microstructure at a nanoscale. The process begins with the synthesis of powders. It is now possible to synthesize powders with a grain size in the nanorange for a wide range of ceramic and metallic compounds from three different ways: (i) physical route such as evaporation-condensation processes and laser pyrolysis [14-21], (ii) chemical route including soft chemistry, sol-gel methods, and hydrothermal synthesis which can be extended to supercritical conditions [22-25], and (iii) the mechanical route in which powders are "nanostructured" (as opposed to those "nanosized"), for example, powders of metallic alloys with a nanodistribution of phases within each particle, can be obtained by mechanical alloying [26-30].

Then, it is necessary to add a consolidation step to obtain dense materials. Different processes have been developed to consolidate nanoparticles [31-34]. Rawers [34] has reviewed 
the main methods to densify nanomaterials and discussed the advantages and disadvantages. All the methods are based on the application of high pressure but also of high temperature to affect densification through particle deformation and mass transport. One promising technique is the hot pressing of mechanically milled powders, in which the careful control of processing parameters (time, temperature, and pressure) makes possible the fabrication of fully dense nanostructured samples $[33,34]$. However, the high-temperature treatment leads to significant grain coarsening (Ostwald ripening). Usually, for limiting the grain growth, it is necessary to decrease the temperature, for example, by the use of very high pressure (4 GPa in some cases) in order to plastically deform the nanometric grains [35]. An alternative route to enhance densification and avoid excessive grain growth is the so-called fast firing method [36] and fast sintering techniques, usually named SPS (spark plasma sintering, [37]). The aim of these methods is to reduce the time of exposure to high temperatures. An example is given in the case of W$2 \mathrm{Y}$ nanopowders prepared by ball milling and then sintered in vacuum [38]. In a recent review containing 1005 papers, Orrù et al. [39] report the potentiality of SPS technology to produce "in a short time" various types of materials. Indeed, SPS is one of the most attractive techniques for producing innovative materials with a moderate cost and, for some cases, enhanced properties [37, 39]. The SPS technique allows rapid heating through Joule effect by applying to the powders and environmental tools (die, punches, and spacers usually in graphite) a high current ( 1000 to $30000 \mathrm{~A})$. It allows producing materials from 10 to 100 times faster as compared to classical powder metallurgy techniques. Rapid heating is performed and sintering is greatly enhanced, allowing the production of a dense material with a limited grain coarsening. Exceptional results are obtained such as a limitation of grain growth in the case of ceramics [40-42], or of metallic composites [43, 44].

The aim of the present research work was to fabricate dense nanostructured nickel in order to take advantage of the improvement of mechanical properties with reduced grain size. One of the challenges was to limit the grain coarsening even in significant size specimens, through the control of the SPS processing parameters (such as heating rate, sintering temperature, holding time, and pressure). However, it is also crucial to control the production of nanopowders in order to get powders having a nanometric size and a size distribution as narrow as possible. Such a control is not obvious due to the large reactivity of nanoparticles. That is why as-milled powders have been produced using high-energy ball milling. Indeed, the milling process leads to both the reduction in the crystallite size and the accumulation of defects in powder particles. The other interest of ball milling is the possibility to form agglomerates with a micrometer size (size usually available with commercial ones) containing nanocrystallites. Moreover, the reactivity towards ambient air of mechanically activated powder in which the specific surface area is reduced in comparison with individual nanoparticles produced, for example, by a chemistry route. Consequently, the storage, the transport, and the handling of mechanically activated $\mathrm{Ni}$ agglomerates are facilitated.

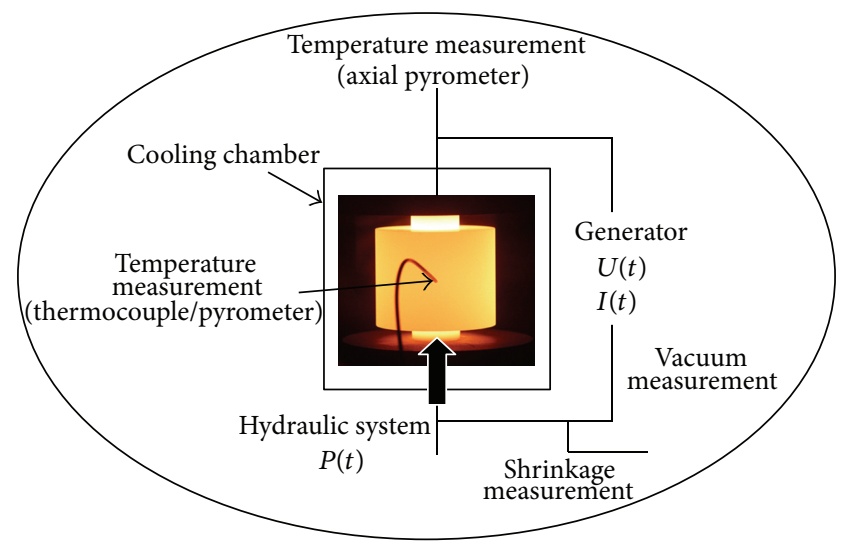

FIGURE 1: Description of the SPS process.

In the present work, Ni milled powders were prepared using high-energy planetary mill and were subsequently consolidated as disk of $50 \mathrm{~mm}$ in diameter using the SPS process, from which tensile specimens were extracted for mechanical characterization.

\section{Experimental Procedure}

The investigation has been performed by evaluating the mechanical properties of nickel samples sintered by SPS from a mechanically activated powder. Mechanical properties are then compared with those of a reference sample obtained by electrodeposition. The process to produce dense nanostructured Ni from a micrometric commercial powder (commercial powder) consists in two steps [45, 46]: (i) mechanical activation of the elemental powder by a short-duration treatment in a high-energy planetary milling (milled powder) and (ii) densification of $\mathrm{Ni}$ in one step by flash sintering using SPS equipment.

The dimensions of sintered specimens must be sufficient to perform tensile tests, that is, $50 \mathrm{~mm}$ in diameter and $10 \mathrm{~mm}$ in height. Conditions of powder preparation were selected to produce per vial one batch necessary to perform one SPS sample. Consequently, $120 \mathrm{~g}$ of elemental powder $\mathrm{Ni}$ (Alfa Aesar, APS 3-7 $\mu \mathrm{m}$ in particle size, $99.9 \%$ purity) was milled in a planetary ball vario-mill Fritsch Pulverisette 4 $[47,48]$. Based on previous works $[49,50]$, a specific ball milling condition was established at $250 \mathrm{rpm}$ (rotation per minute) for the disk rotation speed and $-50 \mathrm{rpm}$ for the absolute vial rotation speed. The charge ratio $C_{R}$ (steel ball to powder mass ratio) was 7 . The powder being constituted of quite abrasive materials, a short duration of milling has been selected to avoid any contamination of the product by the milling tools ( $8 \mathrm{~h}$ uninterrupted). Moreover to limit this contamination but also to increase the yield of nanostructured powder, three millings without cleaning milling tools have been carried out. Under these conditions, the ductile character of powders induced the formation of $\mathrm{Ni}$ coating on the vial surface acting as a protective liner against the abrasion on the surface of tempered iron tools. In addition, the milling parameters were selected to be sufficiently long 


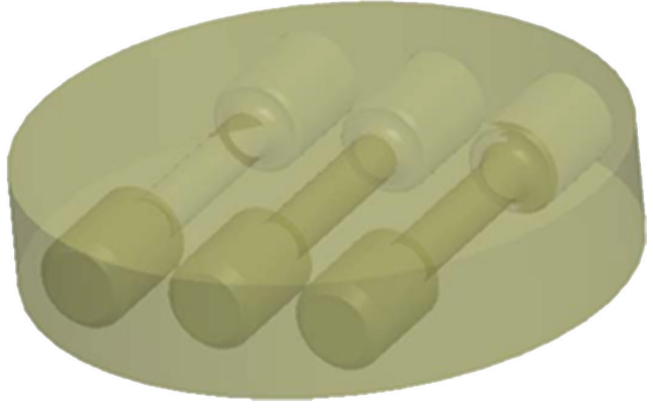

(a)
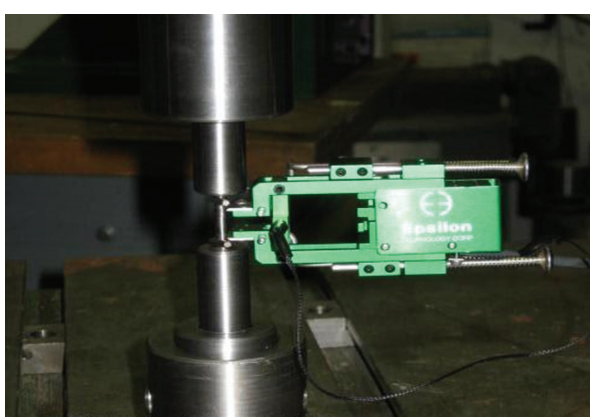

(b)

FIGURE 2: Tensile test: (a) tensile specimens layout in the sintered disc with a diameter of $50 \mathrm{~mm}$ in which three specimens were extracted, (b) tensile specimen with installed extensometer.

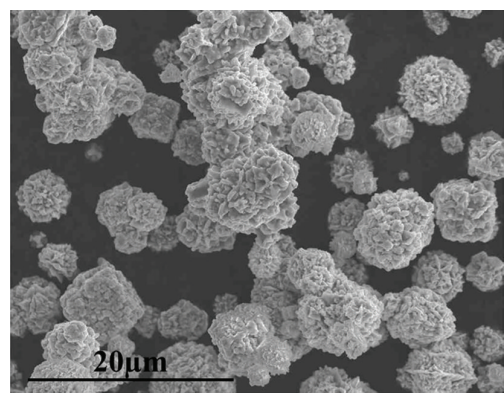

(a)

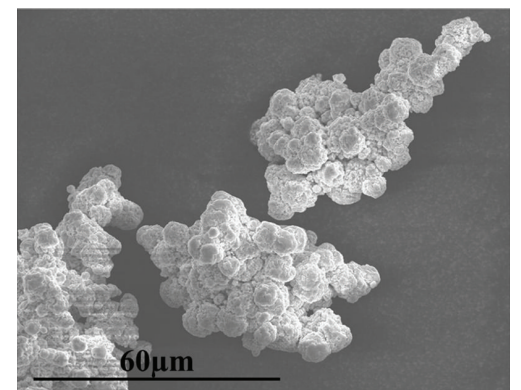

(b)

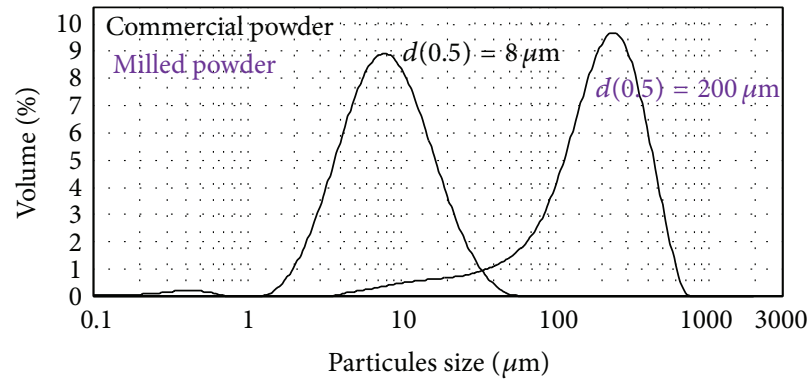

(c)

FIGURE 3: SEM observations of commercial Ni powder (APS 3-7 $\mu \mathrm{m}$ ) and (a) milled Ni powder (b) including the particle size distribution determined by laser granulometry for both systems (c).

for producing mechanically activated agglomerates. Many studies reported the existence of correlation between ball milling conditions and microstructure of milled powders $[51,52]$. It was determined that there is an interval of time for which the crystallite size and the dislocation density are not time dependent whereas the twin faults density increased proportionally to milling duration. Other authors [51] showed that in the case of nanostructured $\mathrm{Cu}$ powder prepared by ball milling a frequency of shocks in range of 6$17 \mathrm{~Hz}$ does not affect the microstructure. On the other hand, crystallite size, dislocation and, twin densities are function of the energy of shocks. From the kinetic model developed by Abdellaoui and Gaffet [48], the change of speed rotations of disk and vials led to an injected power during the ball milling process which can be expressed as the energy of shocks $(E)$ and the frequency of shocks $(F)$. In this work, energy and frequency of shocks are, respectively, equal to $0.08 \mathrm{~J}$ and $9 \mathrm{~Hz}$.

Sintering is the second step and is required to obtain nanostructured materials with a density perfectly controlled. In the case of SPS, the sintering is due to the simultaneous application of direct current pulses of very high intensity (several thousands of amperes) and of a uniaxial pressure to the encapsulating system (Figure 1). The Ni powders were sintered in the spark plasma sintering apparatus (HPD125 apparatus, FCT System GmbH). Dense samples of $50 \mathrm{~mm}$ diameter and $10 \mathrm{~mm}$ thickness were sintered into a graphite die (100 mm outer diameter and $50 \mathrm{~mm}$ height). The powders were first cold compacted in the die lined with graphite foil (graphite foil is also inserted between the powder and the punches) at the sintering pressure during 5 minutes. The die 
containing the cold-compacted sample was enveloped with a carbon felt to reduce the radiation heat losses from the outer surface. The temperature was monitored by a K-type thermocouple located in a hole at $3 \mathrm{~mm}$ far from the sample and half height of the die.

Before characterization, the samples were first polished with 180-grit silicon carbide and up to $1 \mu \mathrm{m}$ with diamond paste and, finally, cleaned in an ultrasonic ethanol bath in order to remove surface contamination from graphite foil. The relative density is obtained by the ratio of the bulk density of the sintered samples (determined using the Archimedes method in distilled water) to the theoretical density. Each value is an average of three measurements. X-ray powder diffraction (XRD) measurements were performed with a Bruker-AXS D8 Advance diffractometer $(\mathrm{CuK} \alpha$ radiation, $\lambda=0.154051 \mathrm{~nm}$ ) using a super speed VANTEC-1 detector. Pattern decomposition was carried out with the profile-fitting program TOPAS using Le Bail's method [49].

A scanning electron microscope (SEM JEOL JSM-7600F) with a field emission gun (FEG) and coupled with (i) a LINK OXFORD Energy Dispersive X-Ray Spectrometry (EDXS) and (ii) an electron backscattering diffraction (EBSD) detector was used to analyze, respectively, the grain morphology and the local chemical composition of materials. The microstructures of powders (commercial and milled) were characterized by embedding and polishing them in order to perform an analysis of the cross section of grains or agglomerates and SPS materials were cut along the axial direction. The samples were observed under secondary or backscattered electron modes and analyzed by orientation imaging microscopy (OIM). The EBSD Kikuchi patterns were posttreated using CHANNEL 5.0 software in order to obtain information on grain size distribution. The grain maps were reconstructed assuming that the real grains contain more than two adjacent pixels with the same orientation and the grain boundary angles were higher than $4^{\circ}$.

Finally, in order to evaluate the mechanical properties, three tensile specimens were extracted from SPS-sintered samples in relation with the schematic representation given on Figure 2. Such a procedure allows us to perform, for each as-sintered material, three tests. The tensile tests were performed at a strain rate of $10^{-3} \mathrm{~s}^{-1}$ with specimens $16 \mathrm{~mm}$ in gage length and $4 \mathrm{~mm}$ in gage diameter using a Testwell machine equipped with a load cell of capacity $5000 \mathrm{daN}$. The gage length elongation was measured with an extensometer Epsilon over a gage length of $10 \mathrm{~mm}$.

\section{Experimental Results}

3.1. Mechanical Activation Stage. The powder issued from the high energy ball milling does not keep the spherical morphology of the commercial powder grains (Figure 3). Mechanically activated powders in comparison to commercial Ni powders appear as large agglomerates due to successive fracture/welding process occurring during the milling. Indeed, the size of commercial powder grain increases from $8 \mu \mathrm{m}$ to $200 \mu \mathrm{m}(d(0.5)$ measured by laser granulometry (Figure 3(c)) whereas the crystallite size determined from

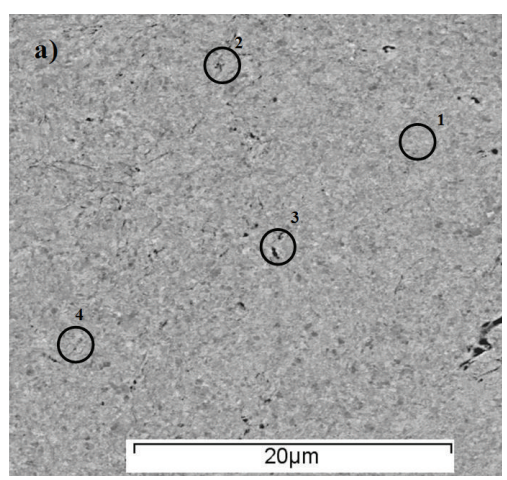

(a)

\begin{tabular}{|c|c|c|c|}
\hline Spot & $\begin{array}{c}\text { At.Ni } \\
(\%)\end{array}$ & $\begin{array}{c}\text { At.O } \\
(\%)\end{array}$ & $\begin{array}{c}\text { At.Cr, Fe (WDS) } \\
(\%)\end{array}$ \\
\hline 1 & 100 & 0 & $<100 \mathrm{ppm}$ \\
\hline 2 & 96.8 & 3.2 & $<100 \mathrm{ppm}$ \\
\hline 3 & 93.8 & 6.2 & $<100 \mathrm{ppm}$ \\
\hline 4 & 100 & 0 & $<100 \mathrm{ppm}$ \\
\hline
\end{tabular}

(b)

FIGURE 4: (a) BSE micrographs showing the transverse cut of milled $\mathrm{Ni}$ agglomerates. The dark zones correspond to oxygen contamination and pores in agreement with (b) EDX analyses reported in the table in which WDS (Fe, $\mathrm{Cr}$ ) analysis were added.

XRD peak profile analysis decreases from $250 \mathrm{~nm}$ to $52 \mathrm{~nm}$. This mechanical activation has allowed the formation of micrometric agglomerates constituted of nanocrystallites. In addition, the microdistortion rate corresponding to an increasing of defect density is also modified but the magnitude seems to be lower $(\sim+10 \%)$. For the selected milling condition, no contamination from the milling tools was detected by both EDX-SEM and XRD analyses. Indeed, two chemical analyses performed by EDX and WDS on milled Niagglomerate confirmed that no $\mathrm{Cr}$ and $\mathrm{Fe}$ contamination was observed. Only few areas located on agglomerate boundary are composed of oxygen (Figure 4). However, oxides are not detected by XRD (in the detection limit of the apparatus). This study confirms the interest to use high-energy ballmilling without cleaning vials in order to avoid any contamination.

Figure 5 obtained from SEM-EBSD analysis permits to determine a grain size distribution (inverse pole figure) and a defect density (kernel analysis) on commercial (Figure 5(a)) and mechanically activated (Figure 5(b)) nickel powders. The white areas on commercial powder figures correspond to the resin. These figures confirm the XRD analyses and show that the high energy ball milling process allows reducing the crystallite size (Figure 5(b)-top). Moreover, many defects have been introduced (Figure 5(b)-down). Indeed, the inverse pole figure for the milled powder exhibits a large grain size distribution including zones containing large grains and others composed with finer grains. In fact mechanical activation of Ni powder allows to obtain a good combination 


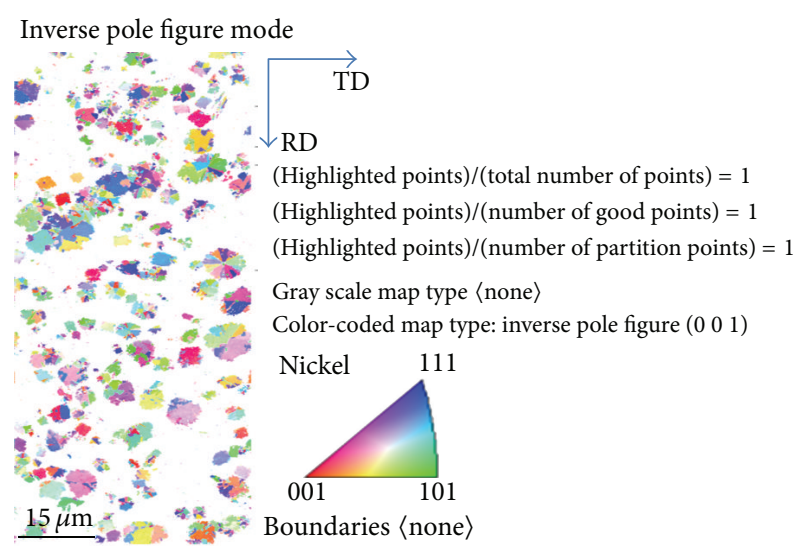

Kernel average misorientation

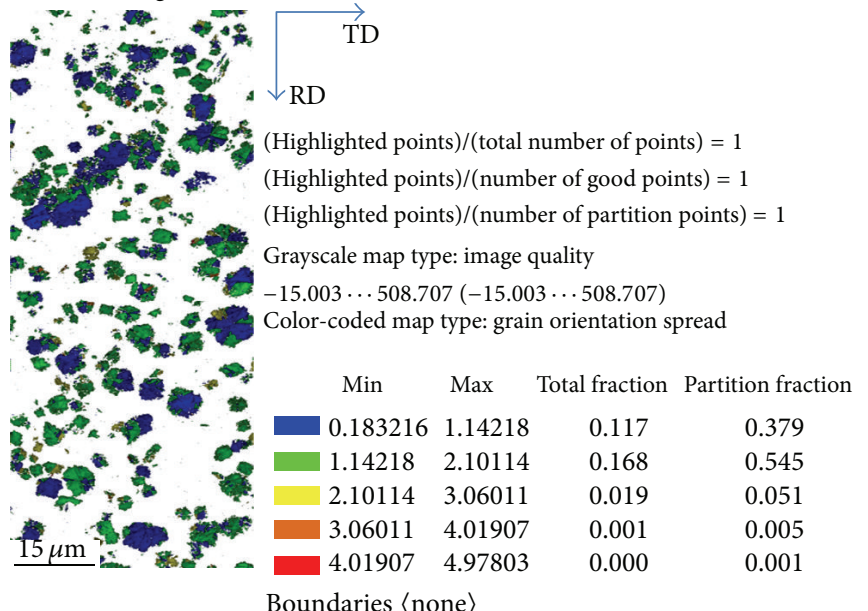

(a)
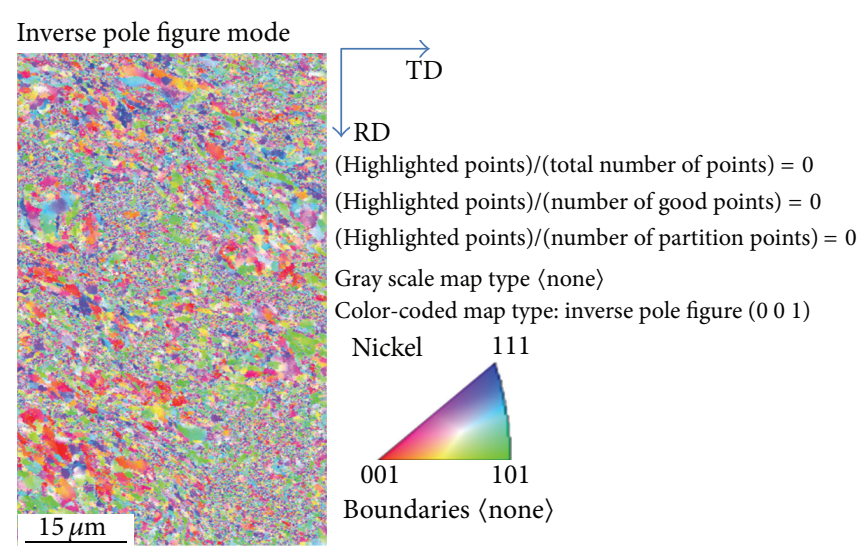

Boundaries 〈none $\rangle$

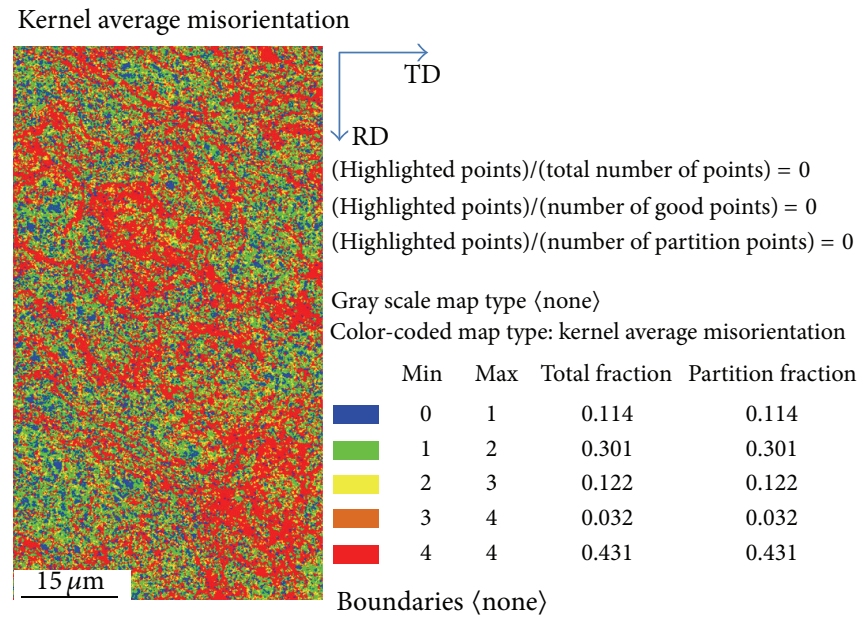

(b)

FiguRE 5: For both (a) commercial and (b) milled Ni powders, inverse pole figure mode and kernel average misorientation have been plotted in order to establish, respectively, the average grain size of particles (top) and a defect density inside powders (down).

between large and fine particles. Moreover, the density of defects introduced during the milling is significant in comparison with commercial powders in which the density of defect is negligible. This density of defects observed on EBSD images is higher than that obtained by XRD analysis for which the contribution of microdistorsion seems to be underestimated. In addition, the lattice strain has been found to increase in the first stage of grain deformation, to reach a maximum, and then to decrease upon further millings $[26,27]$. This behavior has been attributed to strain release which can be observed during the milling especially when the plastic deformation mechanisms are activated via formation and movement of dislocations to grain boundary gliding. Consequently, it is essential to study the influence of the crystallite size reduction and defect density multiplication on the sintering, in particular, on the grain coarsening and consolidation stages.

3.2. Sintering Stage. In order to evaluate the sintering behavior of each powder (i.e., commercial and milled powders), a dilatometric study inside the SPS machine was performed.

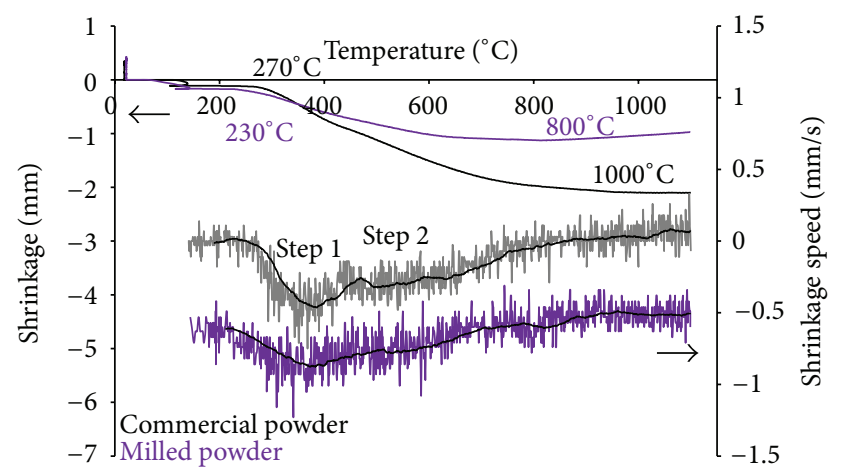

Figure 6: Dilatometric curves of sintering of the commercial powder $\left(270-1000^{\circ} \mathrm{C}\right)$ and the mechanically activated $\mathrm{Ni}$ powder $\left(230-800^{\circ} \mathrm{C}\right)$.

The SPS cycle consisted of a sintering at $1000^{\circ} \mathrm{C}$ under $50 \mathrm{MPa}$ without dwelling time. A heating rate of $50^{\circ} \mathrm{C} / \mathrm{min}$ has been applied. This comparative study presented Figure 6 which shows the sintering behavior of both powders is different. In 


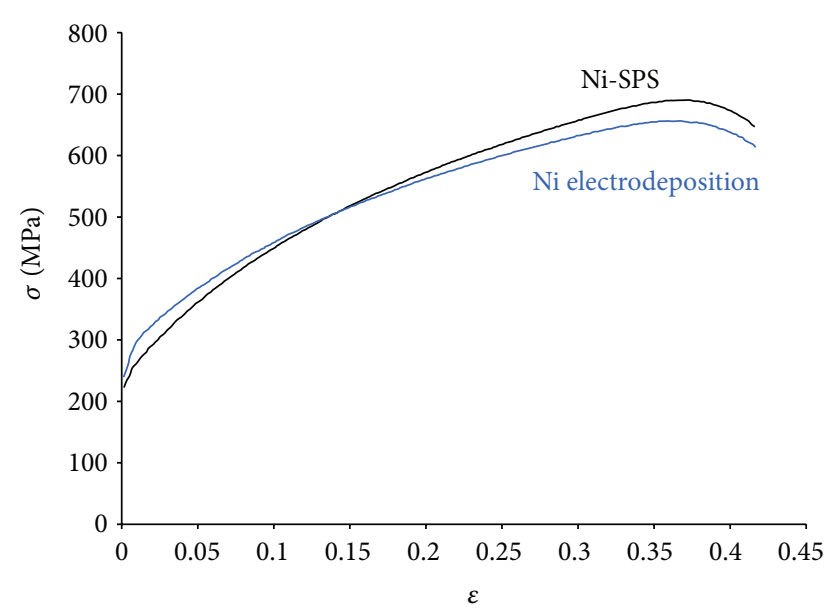

Figure 7: True stress-strain responses of the micrometric Ni prepared by electrodeposition and by SPS.

particular, the temperatures corresponding, respectively, at the beginning $\left(230^{\circ} \mathrm{C}\right.$ instead of $\left.270^{\circ} \mathrm{C}\right)$ and at the end $\left(800^{\circ} \mathrm{C}\right.$ instead of $1000^{\circ} \mathrm{C}$ ) of sintering decrease when a mechanical activation stage on the commercial powder is used. This effect can be attributed to the microstructure difference in terms of crystallite size and defect density as it was observed on EBSD analysis presented on Figure 5. In addition, the shrinkage curve of Ni commercial powder is composed of two steps, firstly between $270^{\circ} \mathrm{C}$ and $400^{\circ} \mathrm{C}$ and secondly between $400^{\circ} \mathrm{C}$ and $1000^{\circ} \mathrm{C}$ whereas such a slope change is not observed for the milled powder (Figure 6).

This different sintering behavior can be explained by the difference of morphology between the two powders. Indeed, the commercial one, due to its thistle-like morphology, has in a first step, and before starting to sinter, its surface which becomes smooth. The optimization of the sintering conditions of the micrometric Ni powder has been performed in a previous work by the establishment of a SPS sintering map $[50-52,59,60]$. Accordingly, the commercial Ni powder was sintered at $750^{\circ} \mathrm{C}$ under $100 \mathrm{MPa}$ during 5 minutes. The heating rate was divided into two steps. The heating rate was $200^{\circ} \mathrm{C} / \mathrm{min}$ until $600^{\circ} \mathrm{C}$ and decreased at $50^{\circ} \mathrm{C} / \mathrm{min}$ for the second step. The density of the sample was $99 \pm 0.5 \%$. Tensile tests were performed on this SPS sintered sample and compared with the reference Ni prepared by electrodeposition ( $99 \%$ dense) (Figure 7). The yield stress, the hardening characteristics, and the ductility of the micrometric SPS sintered specimen and electrodeposition one are totally comparable. Such a comparison validates the SPS process for producing dense nickel with similar properties to the reference material (electrodeposition Ni). Consequently, the sample elaborated from the Ni milled powder has been sintered in the same conditions (sintering parameters and tools). The density of this sintered specimen is equal to $96 \pm 0.5 \%$ only. This density difference could be attributed to the plasticity of the milled powder agglomerates which is smaller than that of the commercial powder. As expected, the nanostructured $\mathrm{Ni}$ sample exhibits a higher mechanical strength than the micrometric sample (Figure 8). A nonnegligible ductility of

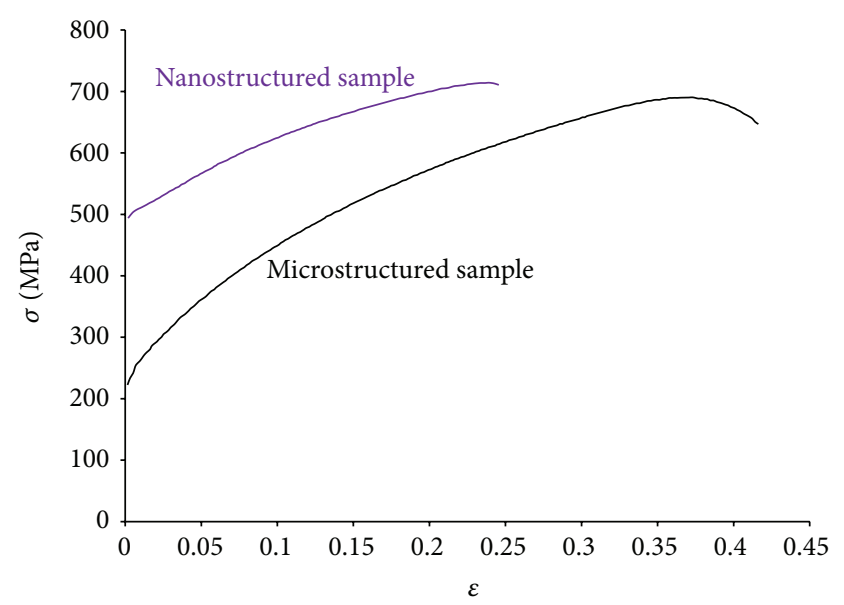

FIgURE 8: True stress-strain response of the microstructured and the nanostructured nickel elaborated by SPS under a pressure of $100 \mathrm{MPa}$.

$25 \%$ was reached with the nanostructured sample. Figure 9 compares the fractographs of the micrometric nickel and the nanostructured nickel both elaborated by SPS under a pressure of $100 \mathrm{MPa}$. They both exhibit stretched voids typical of ductile failure. The micrometric nickel reveals a continuous net of stretched voids of size ranging from 2 to $10 \mu \mathrm{m}$, while the nanostructured nickel reveals a finer stretched void structure with a somehow continuous network of voids ranging from 0.5 to $2 \mu \mathrm{m}$. In addition, the nanostructured nickel exhibits large voids spherical in shape of size ranging from 5 to $10 \mu \mathrm{m}$. Because of their spherical aspects, these voids are believed to originate from pores as the residual porosity is high in excess of $4 \%$.

To improve the density of the sample elaborated from the milled powder, the SPS process has to be optimized. Precisely, the beneficial effect of the SPS process on the densification was demonstrated elsewhere showing that the density is improved with the heating rate, the applied pressure, and the holding time up to a critical value [39]. However, heating rate and holding time do not provide a significant improvement and an increasing of the sintering temperature could lead to grain growth, which will be harmful to the mechanical properties. On the contrary, an increasing of the pressure allows decreasing the sintering temperature while improving densification. So, the strategy adopted has been to apply higher pressure to enhance the contribution of the plastic deformation to densification and bonding. The high stress enhances the plastic strain controlling pore closure. Also, the stress plays a significant role in stress-assisted densification mechanisms. In addition, the extensive plastic deformation under high stress results in the destruction of any continuous surface oxides on powder particles which may degrade bonding and properties. The high pressure applied may also have a beneficial effect of slowing down grain growth because of the reduction of free volumes in grain boundaries which favor atomic jumps across the boundary.

Therefore, the effect of the pressure has been investigated. Because of the poor flexural strength of the graphite, the 


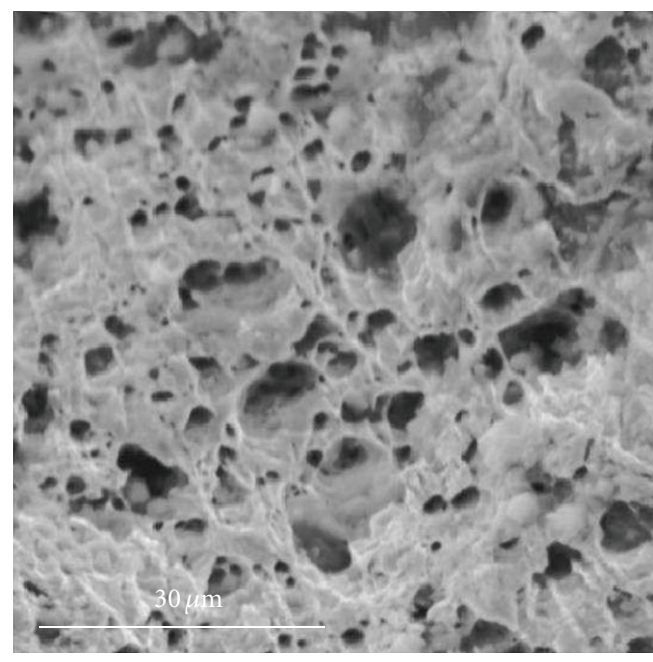

(a)

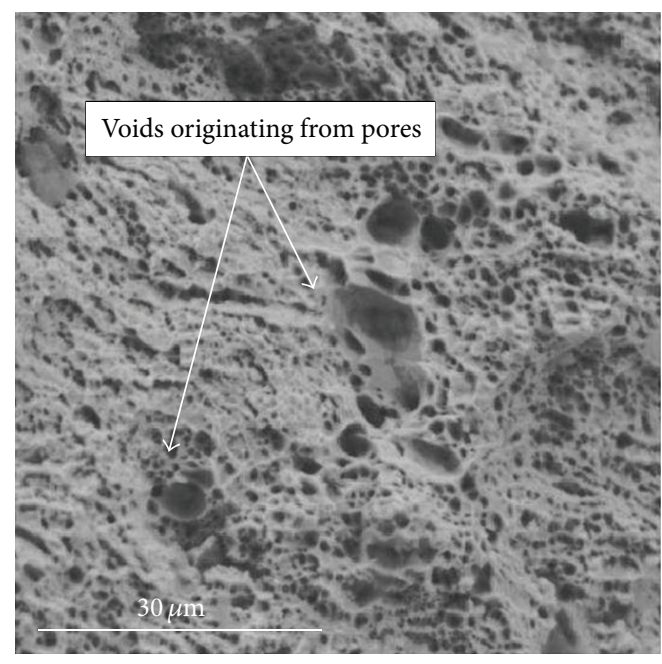

(b)

FIGURE 9: Fractographs of the tensile specimens for the microstructured (a) and the nanostructured (b) nickel elaborated by SPS under a pressure of $100 \mathrm{MPa}$.

uniaxial pressure is limited to $100 \mathrm{MPa}$. Consequently, specific tungsten carbide-cobalt tools including cylindrical die of $100 \mathrm{~mm}$ outer diameter and $50 \mathrm{~mm}$ height and punches have been designed. However, the sample densification is influenced by the nature of SPS tools. Despite a similar sintering temperature, the sample temperature can be different [61]. Therefore, the electrical and thermal conductivities of WC-Co tools impose to modify the thermal cycle applied to mechanically activated Ni powder. In addition, applying very high pressures will strongly affect the sintering behavior by changing the densification temperature. In order to evaluate the influence of the tool on the sintering, a dilatometric curve of the milled powder has been realized from the following sintering conditions: sintering at $700^{\circ} \mathrm{C}$ under $200 \mathrm{MPa}$ with a $200^{\circ} \mathrm{C} / \mathrm{min}$ heating rate without dwelling time. According to this curve the sintering of milled $\mathrm{Ni}$ powder has been performed at $550^{\circ} \mathrm{C}$ during 10 minutes under $200 \mathrm{MPa}$. As previously mentioned, the heating rate was divided into two steps. The heating rate was $200^{\circ} \mathrm{C} / \mathrm{min}$ until $450^{\circ} \mathrm{C}$ and decreased at $50^{\circ} \mathrm{C} / \mathrm{min}$ for the second step. The density of this sample was close to $98 \pm 0.5 \%$.

On Figure 10, it appears that the sintered nanostructured $\mathrm{Ni}$ at $200 \mathrm{MPa}$ has higher mechanical strength $(\sim 590 \mathrm{MPa})$ than the milled powder sintered under $100 \mathrm{MPa}(\sim 500 \mathrm{MPa})$. In addition, the ductility has been improved from 25 to $35 \%$.

As shown in Figure 11, both nanostructured nickel samples exhibit a continuous network composed of stretched voids with size ranging from 0.5 to $2 \mu \mathrm{m}$. For the nanostructured nickel elaborated under high pressure (Figure 11(b)), small spherical voids in size, less than $1 \mu \mathrm{m}$, have been observed as well. However their sizes similar to the size of the stretched voids indicate that the residual porosity may play a minor role in the final failure process of this nanostructured nickel.

Finally, the yield strength of $590 \mathrm{MPa}$ is three times higher than the yield strength of electrodeposition sample. In fact

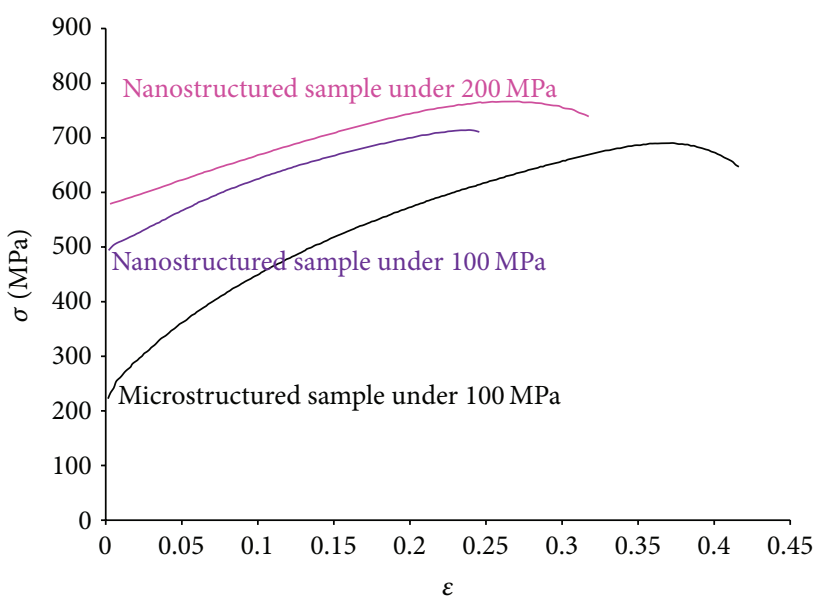

FIGURE 10: True stress-strain response of the micronic sample obtained by electrodeposition and sample obtained by SPS; microstructured nickel and milled nickel under $100 \mathrm{MPa}$ and $200 \mathrm{MPa}$.

the strength observed is approximately consistent with what would be expected under the Hall-Petch relationship. The second interesting feature is that a plastic strain of $30 \%$ is an observed event at this high strength level. Most nanophase nickel alloys (grain size $<100 \mathrm{~nm}$ ) reported previously did not exhibit such pronounced plastic strain before fracture. It is surmised that the premature failure observed in these materials may at least partly be due to the presence of a significant amount of pores, impurities. The behavior of this nanostructured nickel may lead to the presence of "bi-modal" microstructure which is composed of larger grain dispersed in the finer grain matrix as observed on Figure 12.

The EBSD-SEM image on this sample shows clearly these two areas. A sample elaborated in the same conditions but 


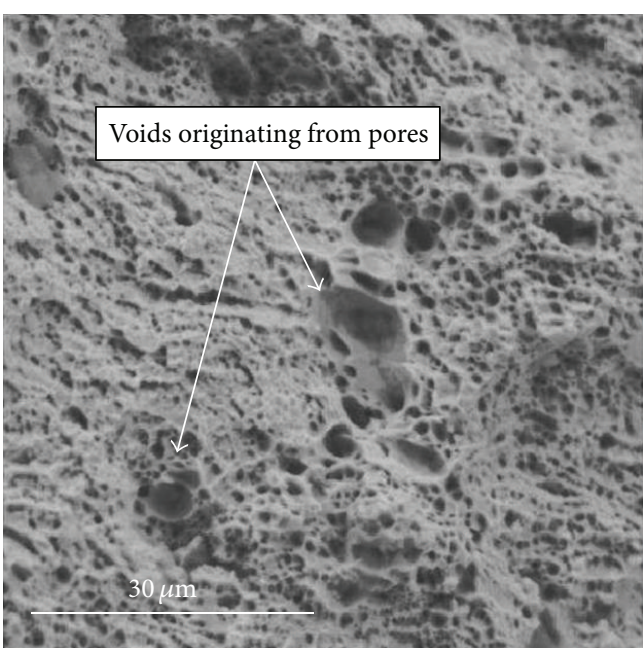

Nanostructured nickel elaborated at a $100 \mathrm{MPa}$

(a)

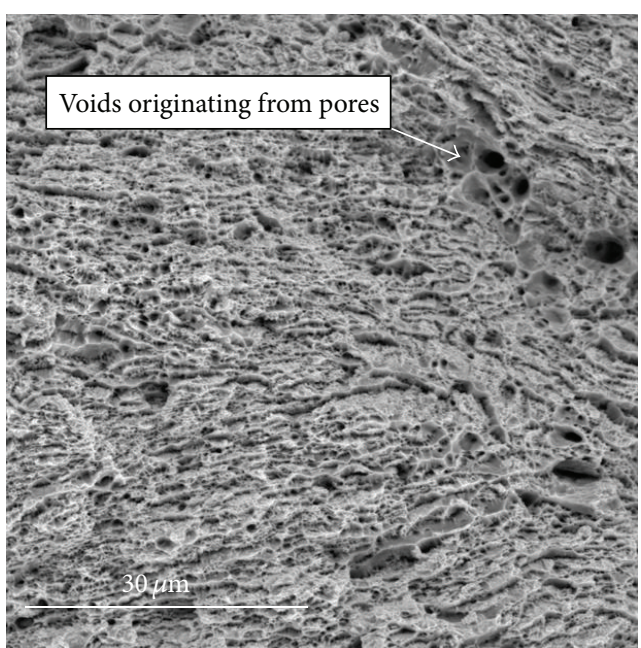

Nanostructured nickel elaborated at a $200 \mathrm{MPa}$

(b)

FIGURE 11: Fractographs of the tensile specimens for the two nanostructured nickels.

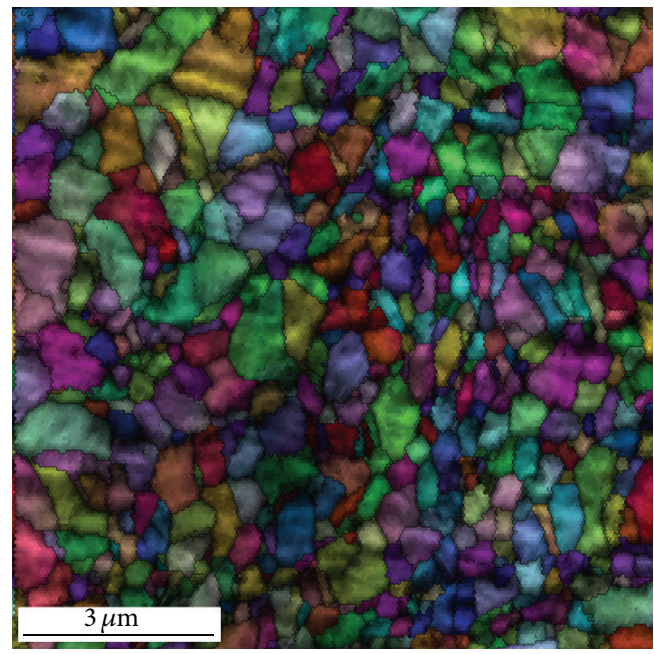

FIGURE 12: EBSD-SEM images of the sample elaborated from the milled powder sintered under $200 \mathrm{MPa}$.

with the commercial powder has a larger and more homogeneous microstructure. Consequently, it will be interesting to control this combination between larger gains and finer ones in order to understand the role of each grain population on mechanical properties especially on strength and ductility. However, in comparison with Hall-Petch plot for nickel processed by different processing routes (Figure 13), it is clearly shown that the dense nanostructured nickel ( $98 \%$ with an average crystallite size of $130 \mathrm{~nm}$ determined by XRD analysis) produced by mechanically activated SPS process is in agreement (our result is symbolized by a open circle) with the dashed line which represents a linear fit on data generated by electrodeposition by Ebrahimi et al. [53] and Xiao et al.

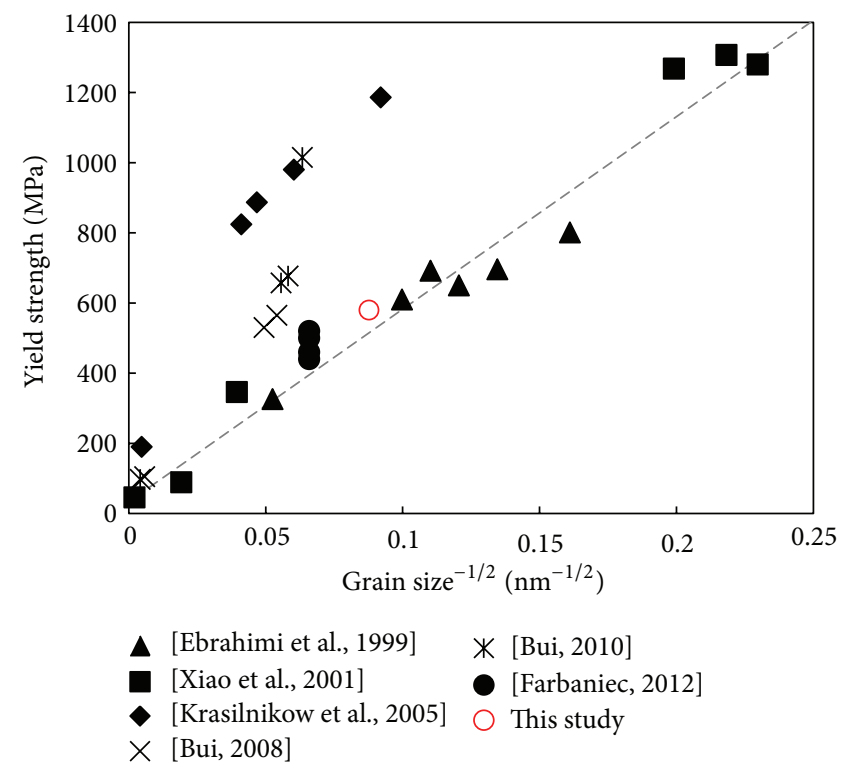

FIGURE 13: Hall-Petch plot for nickel processed by different processing routes (see [53-58]).

[54]. Other data reported in the figure were generated with nanopowders sintered by SPS [55] and HIP [56] and with micrometric nickel plastically deformed by equal channel angular pressing [57] and by dynamic plastic deformation [57]. If the latest technology is another potential mean to generate ultrafined and nanostructured nickel, the sintering of nanopowders, compared to mechanically activated powders, reveals its limitations, as the high density of oxides provides higher strength with a drawback of exhibiting no capacity to deform plastically. 


\section{Conclusion}

The method of dense nanostructured Ni preparation used in the present work is the mechanically activated spark plasma sintering (MASPS). The process to fabricate dense nanomaterials starting from micrometric commercial powders consists in two main steps: (a) mechanical activation (MA) using a high energy ball mill and (b) densification using the SPS device. In the former, mixture of pure elemental powders of $\mathrm{Ni}$ was milled in a Fritsch planetary ball mill (the so-called vario-mill P4 Pulverisette). Finally, the milled nickel powders have been sintered by SPS. The sintering conditions from these mechanically activated powders will be established in order to identify the "SPS window" for which it is possible to consolidate these powders without a coarsening of particles or with a control of the grain growth from a modification of the applied pressure $(200 \mathrm{MPa})$. Consequently, dense nanostructured nickel samples have been produced (98\%). These latter presented a specific and interesting microstructure which combines larger particles with smaller ones.

In addition, in order to use a representative sample for performing mechanical tests, it will be essential to control these nanostructures in larger sample (diameter greater than $50 \mathrm{~mm}$ ). Finally, these Ni nanostructured samples were tested using classical static mechanical tests such as traction tests and compared to the literature data. These nanostructured nickel specimens which had yield strength of $600 \mathrm{MPa}$ with ductility close to $30 \%$ are in agreement with the expected Hall-Petch relationship.

\section{Acknowledgments}

Thanks are due to M. Pascal Vanneau from Nexter Munitions who realized the tensile tests and to MM. Bruno Salesse and Fabien Hemeret from Nexter Systems who performed the fractographies of the tensile specimens. Thanks are also due to M. Frédéric Herbst who performed SEM-EBSD observation and Mme Isabelle Gallet for ball milling preparation.

\section{References}

[1] M. Lahmani, C. Bréchignac, and P. Houdy, Nanomaterials and Nanochemistry, Springer, Berlin, Germany, 2007.

[2] G. Schmid, "Nanoclusters: Building blocks for future nanoelectronic devices?" Advanced Engineering Materials, vol. 3, pp. 737743, 2001.

[3] C. Pirlot, "Preparation and characterization of carbon nanotube/polyacrylonitrile composites," Advanced Engineering Materials, vol. 4, pp. 109-114, 2002.

[4] C. Edser, "Nanopowders seek commercial roles to repay R\&D effort," Metal Powder Report, vol. 54, no. 4, pp. 11-13, 1999.

[5] J. M. Capus, "Prospects look promising for nanopowders," Metal Powder Report, vol. 56, no. 1, pp. 12-14, 2001.

[6] B. H. Kear and G. Skandan, "Overview: status and current developments in nanomaterials," International Journal of Powder Metallurgy, vol. 35, no. 7, pp. 35-37, 1999.

[7] Nanomatériaux, Observatoire français des techniques avancées, 2001.
[8] H. Hahn and K. A. Padmanabhan, "A model for the deformation of nanocrystalline materials," Philosophical Magazine B, vol. 76, no. 4, pp. 559-571, 1997.

[9] E. O. Hall, "The deformation and ageing of mild steel: III Discussion of results," Proceedings of the Physical Society B, vol. 64, no. 9, article 303, pp. 747-753, 1951.

[10] N. J. Petch, “Cleavage strength of polycrystals," Journal of Iron and Steel Institute, vol. 174, pp. 25-28, 1953.

[11] H. Gleiter, "Nanocrystalline materials," Progress in Materials Science, vol. 33, no. 4, pp. 223-315, 1989.

[12] S. Zaefferer, "Investigation of the correlation between texture and microstructure on a submicrometer scale in the TEM," Advanced Engineering Materials, vol. 5, no. 8, pp. 607-613, 2003.

[13] G. Nicolas, "Alliages Lourds de W-Ni-Fe à très haute caractéristiques mécaniques et procédé de fabrication desdits alliages," Brevet FR 262209 (A1), 1989.

[14] J. Bigot, A. G. Goursat, G. Vernet, J. F. Rimbert, J. Foulard, and T. Sarle, 1983, French Patent no. 8307414.

[15] Y. Champion and J. Bigot, "Preparation and characterization of nanocrystalline copper powders," Scripta Materialia, vol. 35, no. 4, pp. 517-522, 1996.

[16] Y. Champion and J. Bigot, "Synthesis and structural analysis of aluminum nanocrystalline powders," Nanostructured Materials, vol. 10, no. 7, pp. 1097-1110, 1998.

[17] M. Umemoto, M. Udaka, K. Kawasaki, and X. D. Liu, "Characterization of mechanically alloyed $\mathrm{Ti}-\mathrm{Zr}-\mathrm{Cu}-\mathrm{Ni}$ powders," Journal of Materials Research, vol. 13, no. 6, pp. 1511-1516, 1998.

[18] Y. Moriysohi, M. Futaki, S. Komatsu, and T. Ishigaki, "The preparation and characterization of ultrafine tungsten powder," Journal of Materials Science Letters, vol. 16, no. 5, pp. 347-349, 1997.

[19] W. R. Cannon, S. C. Danforth, J. H. Flint, J. S. Haggerty, and R. A. Marra, "Sinterable ceramic powders from laser-driven reactions: I, process description and modeling," Journal of the American Ceramic Society, vol. 65, pp. 324-331, 1982.

[20] R. Dez, F. Ténégal, C. Reynaud, M. Mayne, X. Armand, and N. Herlin-Boime, "Laser synthesis of silicon carbonitride nanopowders; structure and thermal stability," Journal of the European Ceramic Society, vol. 22, no. 16, pp. 2969-2979, 2002.

[21] X. X. Bi, B. Ganguly, G. P. Huffman, F. E. Huggins, M. Endo, and P. C. Eklund, "Nanocrystalline $\alpha-\mathrm{Fe}, \mathrm{Fe}_{3} \mathrm{C}$, and $\mathrm{Fe}_{7} \mathrm{C}_{3}$ produced by $\mathrm{CO}_{2}$ laser pyrolysis," Journal of Materials Research, vol. 8, no. 7, pp. 1666-1674, 1993.

[22] J. A. Darr and M. Poliakoff, "New directions in inorganic and metal-organic coordination chemistry in supercritical fluids," Chemical Reviews, vol. 99, no. 2-3, pp. 495-541, 1999.

[23] F. Cansell, C. Aymonier, and A. Loppinet-Serani, "Review on materials science and supercritical fluids," Current Opinion in Solid State and Materials Science, vol. 7, no. 4-5, pp. 331-340, 2003.

[24] Y. Hakuta, H. Hayashi, and K. Arai, "Fine particle formation using supercritical fluids," Current Opinion in Solid State and Materials Science, vol. 7, no. 4-5, pp. 341-351, 2003.

[25] F. Demoisson, M. Ariane, A. Leybros, H. Muhr, and F. Bernard, "Design of a reactor operating in supercritical water conditions using CFD simulations. Examples of synthesized nanomaterials," Journal of Supercritical Fluids, vol. 58, pp. 371-377, 2011.

[26] C. Suryanarayana, "Mechanical alloying and milling," Progress in Materials Science, vol. 46, pp. 1-81, 2001.

[27] E. Gaffet and G. Le Caer, "Mechanical processing for nanomaterials," in Encyclopedia of Nanoscience and Nanotechnology, vol. 1, 
pp. 1-39, American Scientific Publishers, Stevenson Ranch, calif, USA, 2004.

[28] E. Gaffet, F. Bernard, J. C. Niepce et al., "Some recent developments in mechanical activation and mechanosynthesis," Journal of Materials Chemistry, vol. 9, no. 1, pp. 305-314, 1999.

[29] M. Abdellaoui and E. Gaffet, "A mathematical and experimental dynamical phase diagram for ball-milled $\mathrm{Ni}_{10} \mathrm{Zr}_{7}$," Journal of Alloys and Compounds, vol. 209, no. 1-2, pp. 351-361, 1994.

[30] E. Gaffet, M. Abdellaoui, and N. Malhouroux-Gaffet, "Formation of nanostructural materials induced by mechanical processings," Materials Transactions, The Japan Institute of Metals, vol. 36, no. 2, pp. 198-209, 1995.

[31] G. E. Fougere, L. Riester, M. Ferber, J. R. Weertman, and R. W. Siegel, "Young's modulus of nanocrystalline Fe measured by nanoindentation," Materials Science and Engineering A, vol. 204, no. 1-2, pp. 1-6, 1995.

[32] G. E. Fougere, J. R. Weertman, and R. W. Siegel, "Processing and mechanical behavior of nanocrystalline Fe," Nanostructured Materials, vol. 5, no. 2, pp. 127-134, 1995.

[33] J. Rawers, G. Slavens, D. Govier, C. Doǧan, and R. Doan, "Microstructure and tensile properties of compacted, mechanically alloyed, nanocrystalline Fe-Al," Metallurgical and Materials Transactions A, vol. 27, no. 10, pp. 3126-3134, 1996.

[34] J. Rawers, "Comparison of attrition milled, nanostructured, powder-compaction techniques," Nanostructured Materials, vol. 11, no. 4, pp. 513-522, 1999.

[35] J. Eckert, J. C. Holzer, C. E. Krill, and W. L. Johnson, "Structural and thermodynamic properties of nanocrystalline fcc metals prepared by mechanical attrition," Journal of Materials Research, vol. 7, no. 7, pp. 1751-1761, 1992.

[36] K. R. Venkatachari, D. Huang, S. P. Ostrander, W. A. Schulze, and G. C. Stangle, "Preparation of nanocrystalline yttriastabilized zirconia," Journal of Materials Research, vol. 10, no. 3, pp. 756-761, 1995.

[37] M. Tokita, “Trends in advanced SPS spark plasma sintering systems and technology: functionally gradients materials and unique synthetic processing methods from next generation of powder technology," Journal of the Society of Powder Technology, Japan, vol. 30, pp. 790-804, 1993.

[38] M.-N. Avettand-Fenoël, Influence des Paramètres de Broyage et de Frittage sur la Microstructure d'Alliages O.D.S à Base de Tungstène [Ph.D. thesis], 2003.

[39] R. Orrù, R. Licheri, A. M. Locci, A. Cincotti, and G. Cao, "Consolidation/synthesis of materials by electric current activated/assisted sintering," Materials Science and Engineering $R$, vol. 63, no. 4-6, pp. 127-287, 2009.

[40] Z. Shen, M. Johnsson, Z. Zhao, and M. Nygren, "Spark plasma sintering of alumina," Journal of the American Ceramic Society, vol. 85, no. 8, pp. 1921-1927, 2002.

[41] G. Bernard-Granger and C. Guizard, "Spark plasma sintering of a commercially available granulated zirconia powder: I. Sintering path and hypotheses about the mechanism(s) controlling densification," Acta Materialia, vol. 55, no. 10, pp. 3493-3504, 2007.

[42] N. Millot, S. Le Gallet, D. Aymes, F. Bernard, and Y. Grin, "Spark plasma sintering of cobalt ferrite nanopowders prepared by coprecipitation and hydrothermal synthesis," Journal of the European Ceramic Society, vol. 27, no. 2-3, pp. 921-926, 2007.

[43] G. Cabouro, S. Chevalier, E. Gaffet, D. Vrel, N. Boudet, and F. Bernard, "In situ synchrotron investigation of $\mathrm{MoSi}_{2}$ formation mechanisms during current-activated SHS sintering," Acta Materialia, vol. 55, no. 18, pp. 6051-6063, 2007.
[44] G. Ji, T. Grosdidier, F. Bernard, S. Paris, E. Gaffet, and S. Launois, "Bulk FeAl nanostructured materials obtained by spray forming and spark plasma sintering," Journal of Alloys and Compounds, vol. 434-435, pp. 358-361, 2007.

[45] Z. A. Munir, F. Charlot, F. Bernard, and E. Gaffet, "Onestep synthesis and consolidation of nano-phase materials," U.S Patent no.6, 200,515, March 2001.

[46] G. Ji, F. Bernard, S. Launois, and T. Grosdidier, "Processing conditions, microstructure and mechanical properties of heteronanostructured ODS FeAl alloys produced by SPS," Materials Science and Engineering, vol. 559, pp. 566-573, 2013.

[47] M. Abdellaoui, T. Barradi, and E. Gaffet, "Mechanism of mechanical alloying phase formation and related magnetic and mechanical properties in the FeSi system," Journal of Alloys and Compounds, vol. 198, no. 1-2, pp. 155-164, 1993.

[48] M. Abdellaoui and E. Gaffet, "The physics of mechanical alloying in a planetary ball mill: Mathematical treatment," Acta Metallurgica Et Materialia, vol. 43, no. 3, pp. 1087-1098, 1995.

[49] A. Le Bail, H. Duroy, and J. L. Fourquet, "Ab-initio structure determination of $\mathrm{LiSbWO}_{6}$ by X-ray powder diffraction," Materials Research Bulletin, vol. 23, no. 3, pp. 447-452, 1988.

[50] L. Minier, Influence du Frittage "Flash" sur l'Obtention de Nanostructures dans des Systèmes Métalliques et Céramiques [Ph.D. thesis], Université de Bourgogne, 2008.

[51] H. Couque, L. Minier, C. Wolff et al., "High strain rate response of nanostructured and microstructured nickel elaborated by SPS," in Proceedings of the 18th DYMAT Technical Meeting, H. Couque, Ed., pp. 57-64, 2008.

[52] O. Boytsov, A. I. Ustinov, E. Gaffet, and F. Bernard, "Correlation between milling parameters and microstructure characteristics of nanocrystalline copper powder prepared via a high energy planetary ball mill," Journal of Alloys and Compounds, vol. 432, no. 1-2, pp. 103-110, 2007.

[53] F. Ebrahimi, G. R. Bourne, M. S. Kelly, and T. E. Matthews, "Mechanical properties of nanocrystalline nickel produced by electrodeposition," Nanostructured Materials, vol. 11, no. 3, pp. 343-350, 1999.

[54] C. Xiao, R. A. Mirshams, S. H. Whang, and W. M. Yin, "Tensile behavior and fracture in nickel and carbon doped nanocrystalline nickel," Materials Science and Engineering A, vol. 301, no. 1, pp. 35-43, 2001.

[55] Q.H. Bui, Polycristaux à Grains Ultrafins Élaborés par Métallurgie des Poudres: Microstructure, Propriétés Mécaniques et Modélisation Micromécanique [Ph.D. thesis], University of Paris 13, Villetaneuse, France, 2008.

[56] Q. H. Bui, G. Dirras, S. Ramtani, and J. Gubicza, "On the strengthening behavior of ultrafine-grained nickel processed from nanopowders," Materials Science and Engineering A, vol. 527, no. 13-14, pp. 3227-3235, 2010.

[57] N. Krasilnikov, W. Lojkowski, Z. Pakiela, and R. Valiev, “Tensile strength and ductility of ultra-fine-grained nickel processed by severe plastic deformation," Materials Science and Engineering A, vol. 397, no. 1-2, pp. 330-337, 2005.

[58] L. Farbaniec, Deformation Mechanisms and Fracture Strength of Polycrystalline Ultrafine-Grained Materials: Experimental and Numerical Investigations [Ph.D. thesis], University of Paris 13, Villetaneuse, France, 2012.

[59] P. Scardi, M. Leoni, E.J. Mittemeijer, and P. Scardi, Diffraction Analysis of the Microstructure of Materials, Springer, Berlin, Germany, 2003. 
[60] L. Minier, S. Le Gallet, Y. Grin, and F. Bernard, "Influence of the current flow on the SPS sintering of a Ni powder," Journal of Alloys and Compounds, vol. 508, no. 2, pp. 412-418, 2010.

[61] L. Minier, S. Le Gallet, Yu. Grin, and F. Bernard, "A comparative study of nickel and alumina sintering using Spark Plasma Sintering (SPS)," Materials Chemistry and Physics, vol. 134, pp. 243-253, 2012. 

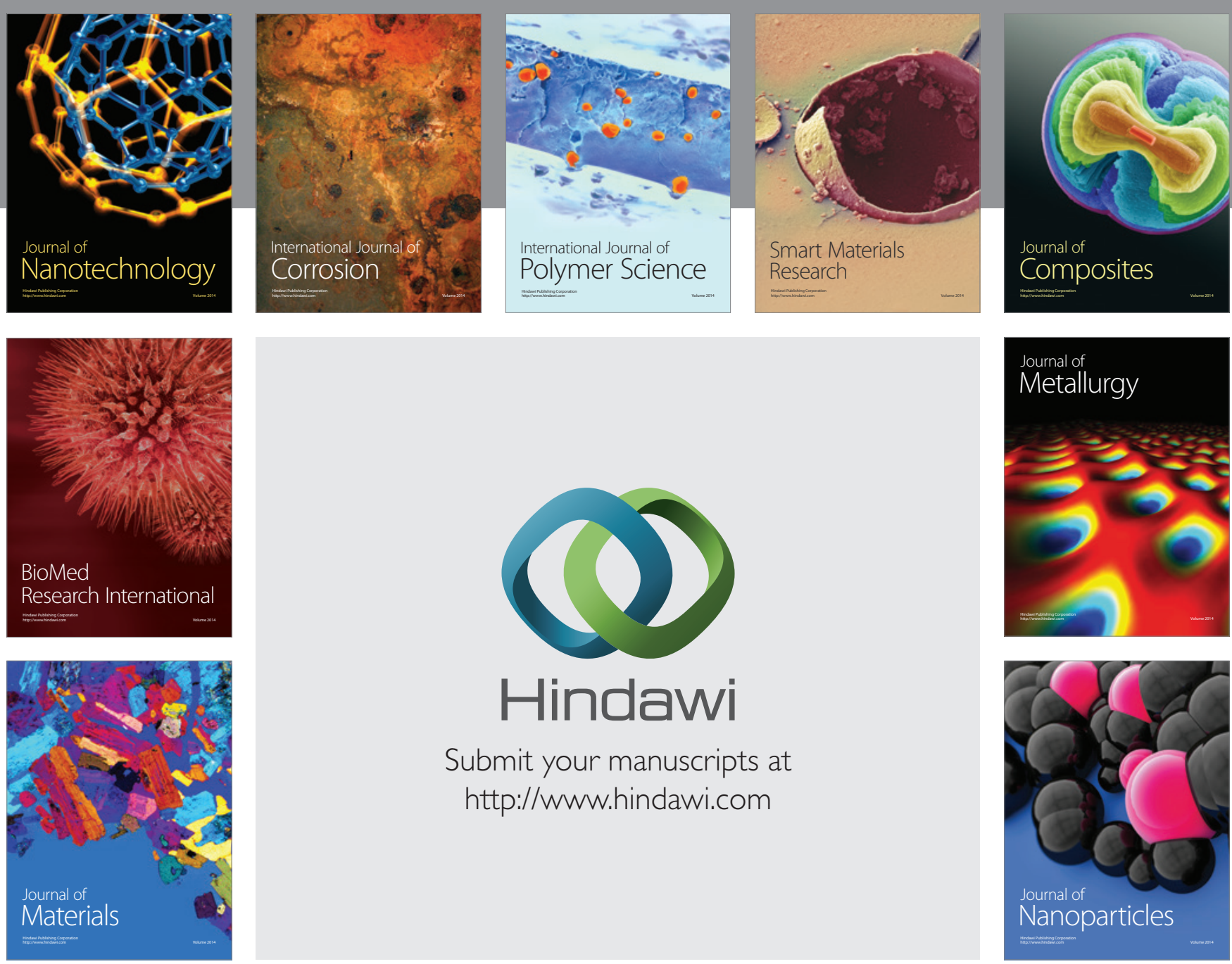

Submit your manuscripts at http://www.hindawi.com
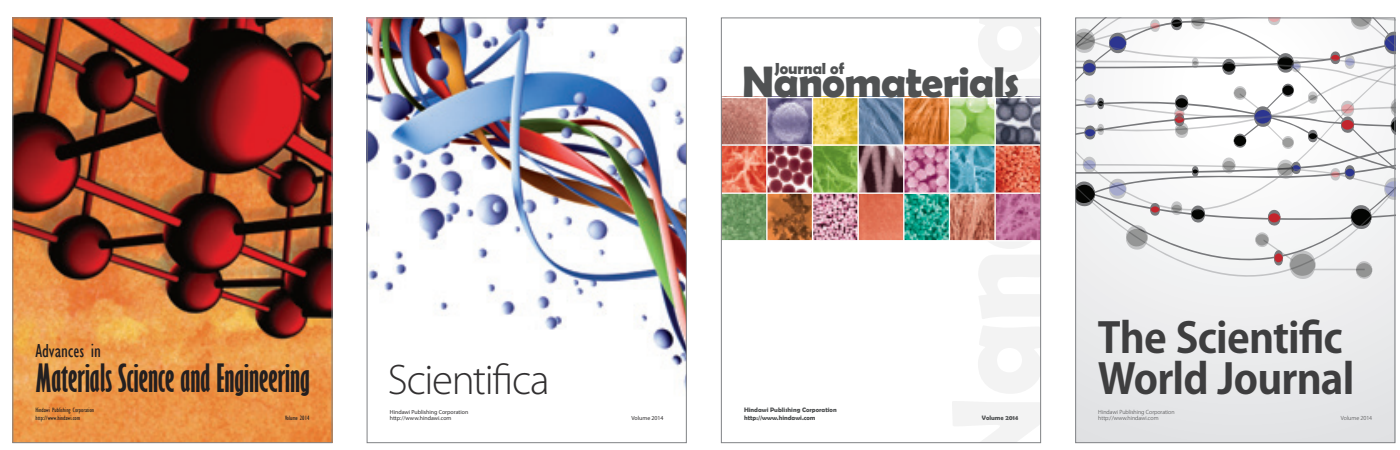

\section{The Scientific World Journal}
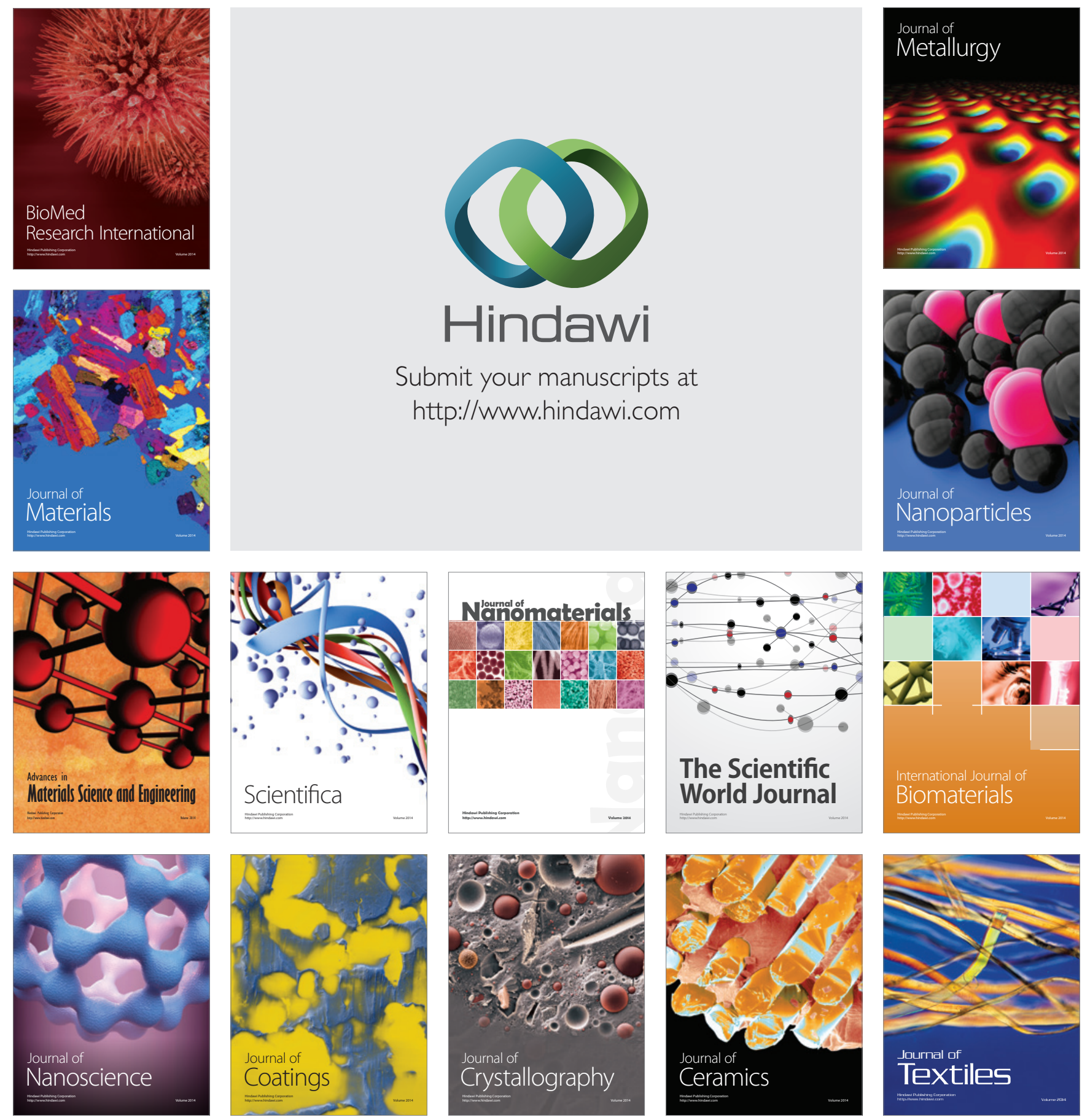